\title{
Strategies to Teach Sight Words in an Elementary Classroom
}

\author{
Rachel Blackwell ${ }^{1, *} \&$ Sarah Laman ${ }^{2}$ \\ ${ }^{1}$ Educational Specialist in Elementary Education, University of West Georgia, 1601 Maple St. \\ Carrollton, GA 30118, USA \\ ${ }^{2}$ Candidate for Masters in Education, University of Science Arts and Technology \\ *Corresponding author: Tel: 1-404-771-9982 E-mail: Rb2mm129@yahoo.com
}

Received: July 17, 2013 Accepted: September 18, 2013 Published: October 22, 2013

doi:10.5296/ije.v5i4.4024 URL: http://dx.doi.org/10.5296/ije.v5i4.4024

\begin{abstract}
The theoretical framework within which this article defines and describes the teaching of reading in early childhood education is derived from the work Ehri (1995). Ehri is professor of educational psychology at New York University. Professor Ehri describes four phases to the process of learning how to read. The four phases are pre-alphabetic, partial alphabetic, full alphabetic, and consolidated alphabetic (Ehri, 1995). Once the reader has gone through these four stages, they are then able to move forward towards fluency in reading by memorizing sight words. At the end of these processes the student will then be able to achieve literacy.
\end{abstract}

Keywords: sight words; dolch list; reading 


\section{Phases of Sight Word Development}

There are four distinct phases in the development of sight words (Gaskin, Ehri, Cress, O'Hara \& Donnelly, 1997). These phases are characterized by the type of alphabetic knowledge used to form neural connections. The four phases are: pre-alphabetic, partial, full, and consolidated alphabetic phases (Ehri, 2005). Ehri has extensively developed and researched the commonalities that underlie the written forms of English words. Dr. Ehri believed that all learners must go through all four phases in the development of sight words before beginning the process of memorizing them (Ehri, 1995). When a child masters the pre-alphabetic, partial, full and consolidated alphabetic phases they are able to form connections in their brain that link the written word forms of the sight word to their pronunciation and meanings (Ehri, 1995). With each phase in development, the connection forming process is evident and helps children put the word into sight memory.

\subsection{Pre-Alphabetic Phase}

The first phase of sight word development consists of the pre-alphabetic phase. Children at this phase have not developed any alphabet knowledge.Instead, children at this phase read sight words by remembering the visual cues around or in the word (Gaskin, Ehri, Cress, O'Hara \& Donnelly, 1997). Children in this phase are essentially nonreaders and do not use the alphabetic system. Children that read words do so because the words have very distinct visual clues (Ehri, 2005).

\subsection{Partial Alphabetic Phase}

The second phase in the four-phase progression of sight word learning is the partial alphabetic phase. Progression to the partial alphabetic phase occurs when children sufficiently learn the sounds and names of the alphabet letters (Ehri, 2005). However, they still have difficulty decoding unknown or unfamiliar words because they lack the knowledge of vowels and rules pertaining to the alphabet (Gaskin, Ehri, Cress, O'Hara \& Donnelly, 1997).

Children in this phase find connections with certain letters in the words. Generally, the easiest letter sounds in a word are the first and last letters because they are the most prominent (Savage, Stuart, \& Hill, 2001). Children will often pick out those first and last letters to associate with the word itself.

Such a skill is progress towards reading fluency; however. it is a very inconsistent technique and can lead to reading errors. For example, if a child learned to read the word "kitten" by letter association using the $\mathrm{K}$ and $\mathrm{N}$ and was then presented with the word kitchen, the child might misread that word as kitten.

\subsection{Full Alphabetic Phase}

When a reader enters the third stage of the four steps of reading development, they are able to "analyze the spellings of words by matching up all the letters to sounds in pronunciations" (Gaskins, Linnea, Cheryl , Colleen \& Katharine, 1997, p. \#). In this phase, the reader is able to 
make complete connections with the letters and the written form of words. These readers are able to decode unknown words.

\subsection{Consolidated Alphabelic Phase}

The fourth and final phase of sight word development is called the consolidated alphabetic phase. In this phase, children are able to retain more sight words by memory. They have a firm foundation in the letters sounds, and are able to group certain letters together instead of sounding out each phoneme. This phase is important because larger words, words with more letters, are more difficult to read if the reader has not memorized a certain percentage of common words or associated "ing" and "ed" type endings. For example, the word "running" is a much bigger word than "run" the difference is the "ing" at the end which makes reading the word more difficult because it has more letters. When readers have memorized what "ing" stands for, they can efficiently read the word "running" just as well as the word "run" without having to pause. Ehri stated that "Readers who know the relevant chunks can learn a word such as interesting more easily, because fewer connections are required to secure the word in memory. The number is reduced from 10 phonemes to four syllabic chunks" (Ehri, 2005, p. \#).

\section{Memorizing Sight Words}

Learning to read is a complex and often difficult task for children. The reading process consists of learning to decode words and learning to read words by sight. Decoding is the process of knowing and realizing that written letters have relationships to sounds and are learned through phonics instruction. After the acquisition of letter sounds, children then are able to decode, break the words apart by sound, and then blend the sounds together to read the word quickly (Rubin \& Opitz, 2007; Vacca, Vacca, Gove, Burkey, Lenhart \& McKeon, 2009).

Learning to read by sight is learning to recognize words and read them quickly without decoding. Retrieving and reading words quickly with meaning enables a person to read fluently. Although there is not a true definition of what fluency is, the National Institute of Child Health and Human Development (2000) stated that fluency is the ability to read quickly, accurately, and with expression. Johnston (2000) asserted that students who retrieve words effortlessly by sight are able to read text easily with more meaning and capable of learning many more new words. This is imperative because a large portion of words including many of the Dolch sight words cannot be sounded out using the rules taught within phonics instruction.

Motivating and actively engaging students in reading activities is an important part of teaching reading skills. A recent national survey of teachers revealed that "creating interest in reading was rated as the most important area for future interest" (Gambrell, 1996). Students who are not actively engaged in learning may become bored and lose their motivation and interest. Downtime in the classroom worsens this problem. The ramifications extend further than wasted time and frustration. Such ramifications range from unfocused and disruptive children to the loss of interest in future reading and lower comprehension skills later in life. Adults who have poor literacy rates are linked to failure of societal contributions through lingering 
unemployment (Law, Rush, Shoon \& Parsons, 2008) and behavioral problems (Arnold, Golston, Walsh, Reboussin, Daniel, Hickman \& Wood, 2005).

\section{Sight Word Learning Theory}

Sight words are words that can be read through sight from recalled memory. Decoding, analogizing, or predicting words take a conscious effort from the reader, which then brings focus to the meaning of the word itself, not the context it is in, which impedes comprehension.

Therefore, building a sight word vocabulary is important for children if they're to become efficient and effective readers. (Browder \& Lalli, 1991)

Throughout the years, researchers have been trying to explain how beginning readers are able to recognize sight words rapidly and automatically. Ehri agreed that the method of sight-word reading differs from the phonemic used to decode unknown words (Ehri, 2005). The act of reading is carried on by memory processes, not decoding processes (Gaskin, Ehri, Cress, O'Hara, \& Donnelly, 1997). Mature readers read most efficiently and effectively through memory, not through sounding each word out phonetically. The advantage of sight-word reading over decoding is that sight-word reading is much faster (Ehri, 1995) and thus fluency in reading is achieved.

\section{Methods of Teaching Sight Words to Children}

There is a clear need for sight word recognition in kindergarten-aged children (Conners, 2003). In the United States, such formal genesis of learning sight words generally begins in kindergarten; to contribute to literacy success within such a population, application of empirical based research supporting operative teaching techniques of sight words must be present to guide teachers in efficient and effective teaching strategies. Children learn to read in different ways, therefore, different teaching methods must be employed (Grossen, 1997).

\subsection{Traditional Flash-Card Method}

Traditional flash card methods of teaching have been widely accepted over the years and are supported throughout the teaching community as an effective technique that facilitates student learning. In this method a sight word is written on a flashcard; the teacher flashes the word to the children; and the children should automatically read the word on the card. This procedure is done over and over resulting in a flashcard method. Repetition employing the flash card method is effective (Casey, S. D. 2008) in enabling student's recognition of sight words; however, it may not be the most efficient way of teaching sight words (Anderson, M., Kupzyk, S., Daly. 2011). Additionally, it has been argued in the journal Early Childhood Today that mere rote memorization of such words absent of interaction may lead to a deficit in reading enjoyment and empathy. 


\subsection{Picture-Based Methods}

Picture-supported teaching methods utilize pictures to help children understand words. These pictures are generally a direct illustration of the presented word as the below graphic (Meadan, Stoner, Parette, 2008).

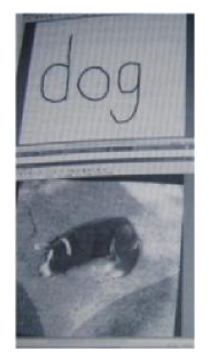

Other times, this method may use a combination of a word morphed into a picture in which the letters become an illustration of what the word represents. The letters are physically manipulated in different planes of space to illustrate the meaning of the word. An example of this combination of morphing words into pictures is illustrated in the graphic below (Sheehy 2005),

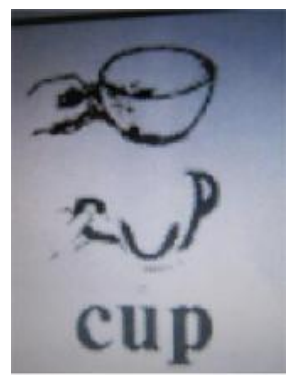

Figure 1: Morphing words into pictures. An example of this combination of morphing words into pictures (Sheehy MOS)

Koorland and Fueyo (2002) conducted a study that focused on Dolch sight words and pictures. The focus of the study was teaching Dolch sight words with a fading procedure by using pupil-generated prompts. During the first treatment session, the researcher read the word and discussed the meaning of the word. The word was spelled precisely and used in a sentence. The participant drew a picture that depicted the sight word. This activity was modeled by the researcher. Then the participant made a card for each of the Dolch sight words, using 5x8 index cards with eight different colored markers. In the second treatment, the participant made new cards for the same word list but used smaller cards, $4 \times 6$, and only had a box of 16 crayons and 8 colored pencils. This was the fading process. In the third and final treatment, the participant used 3 x 5 index cards and only wrote the word with a black marker. This process was continued with a second and third set of sight words. All treatment sessions lasted 20 minutes. The participant's achievement of recognizing sight words combined with pupil-made pictures improved with each set of words; a high degree of retention was maintained within each set of words. The researchers suggested that the increase of sight-word recognition within this model could be because the participant was actively engaged in physical 
movements and employed more sensory avenues while drawing his or her own pictures. Furthermore, during the drawing process, the participant gave detailed attention to his drawings, which took the sight words from an abstract level to a concrete level: this process improved recognition of words.

Mcaden, Stoner, and Parette (2008) investigated sight-word instruction combined with picture-supported techniques as compared to word-only methods in a Midwestern city. The participants were 4 and 5 years old from seven different preschool classrooms for at-risk children. The participants were randomly assigned to either a control group or an intervention group. Both groups were given the same Dolch words to learn over a four week period. Both groups were picture- and word-only supported and played games such as bingo and shake, drop, and roll. The only difference was that the picture supported group-used pictures to represent the Dolch sight words. The outcome of the research seemed to demonstrate that the control group, were the only group learned faster and showed progress quicker. But in the final assessment, the experimental group read more Dolch sight words correctly. The intervention group showed their growth in the later part of the research rather than in the beginning. The control group seemed to move ahead enthusiastically but the intervention group retained more knowledge over a longer period of time. Careful analysis of why the control group learned words quicker but did not retain correct comprehension, demonstrating that the flashcard alone process increases speed, whereas picture-supported reading resulted in correct retention showing that participants used the picture to mentally retrieve and comprehend the word. This study concluded that while flashcards can increase speed, flashcards together with pictures can increase both accuracy and speed.

Alternatively, there have been studies that demonstrate that pictorial prompts have blocked the learning of Dolch sight words. Didden, Prinsen, and Sgafoos (2000) completed a study with six moderate mentally handicap participants between the ages of 7 and 9 years old. Didden et al. (2000) found that participants were able to name pictures but were unable to read the words prior to interventions. However, during interventions, when picture and words were presented together, difficulty in word recall occurred. This could have been caused by the simple fact that participants were focusing on the details of the picture and not concentrating on the printed sight words. Given the description of the sample in the study, the research conclusions may not be applicable to the entire generalized population but still addresses children of elementary school age who may have difficulties with reading or undiagnosed learning disabilities. The National Institute for Literacy states that 30 to $50 \%$ of the population has an undiagnosed learning disability. The U.S. Department of Education released a statement published in 2011 that estimates approximately $13.1 \%$ of the total public school population in America has one or more diagnosed learning disabilities. Between diagnosed and undiagnosed learning disabilities, varied teaching strategies must be utilized to reach above the generalized population. The goal of a teacher is to properly educate all children in the classroom, not just the majority (Didden et al., 2000). 


\subsection{Technology-Based Methods}

Technology-supported teaching methods allow the teacher to use electronics as an aid to deliver teaching curricula. Electronic aids can range from computers with PowerPoint software to interactive SMART boards with touch-screen capabilities.

Technological aids, such as SMART boards are becoming popular because of the boards' interactive capabilities in combining multiple teaching methods. Gast, Waling, and Thompson (2008) completed a study using a SMART board with three special education students who were enrolled in a transition program for young adults on a university campus. Students were selected for the study based on their IEP objectives of increasing functional sight word vocabulary. The participants consisted of a female diagnosed with a moderate intellectual disability with an IQ of 54. The second participant was another female diagnosed with Down syndrome and a moderate intellectual disability with an IQ of 53 The third participant was a male diagnosed with athetoid cerebral palsy and a moderate intellectual disability with an IQ of 52. Words were either correct if said within 3 seconds or incorrect if not read within 3 seconds. Participants were in sessions 3 and 4 days a week in the morning and afternoon_ Sessions lasted about 15 minutes for an individual session and 30 minutes for small group sessions. Participants were to read target words, match grocery item photos to target grocery words, read other students' target grocery words through observational learning, and match grocery item photos to observational grocery words. Results showed an increase in correct reading and matching of each set of target words using SMART Boards with the three second time delay. The success of this study, which involved multiple participants, is directly related to the SMART board and its ability to project images on a large interactive touch screen. This enables multiple participants to view information at the same time, which supported the delivery of target information and learning of other participants by making images more visible and increasing attention.

In a different type of technology-based research design, Sheehy (2005) completed a study comparing the teaching of sight words without pictures to a morphing technique with images for teaching sight words. The participants were children with severe learning disabilities. They ranged in age from 8 to 16 years old; all participants attended a school for students with disabilities. Several of the students used signing to support their language. None of the students had an existing established sight-word vocabulary. Each participant was taught six words using a morphed and word-alone condition. Words and corresponding pictures were loaded into the WinMorp computer program. In the word-only condition, participants were shown modeled words while being shown the word. The participants offered a contextual meaning of the word to assist in morphing words in context. The words were presented again. If the words were not read correctly, they were modeled for the participant. In the morphed words, the words were presented on a computer screen and were morphed. If the word was not named, the word was modeled and prompted to read the word again. This process took place 4 days a week for a 3-week period. The overall results showed that the morphed words approach was superior to the word-alone method in increasing students sight vocabulary. Morphing takes the abstractness of the sight word and creates a concrete visual. This makes sight words 
to become more meaningful and applicable in the participants' working vocabulary in spoken and written form. This study also supports a creative twist to the basic flashcard method.

\subsection{Game Based Methods}

Game-based teaching methods can be defined as follows: the use of a game to deliver lesson material either during regular instruction or in between lessons when games are defined as an enjoyable activity by the participant(s). Game-based learning has demonstrated great effectiveness in helping children recognize value in the material learned, increase student's motivation to learn, and help struggling students grasp difficult concepts by encouraging them to not quit (Charlton, McLaughlin \&2005). Game-based teaching can be implemented in many different ways and need not require pricey commercial games. The Charlton et al. (2005) study used a mixture of commercially produced and teacher-created games and found no difference between the two outcomes, as both were shown to accelerate the participants progress in recognition of sight words. In fact, the authors of the Charlton et al. (2005) study discussed the possibility that teacher made games were even more effective than the commercially produced games because the teacher made games could be directed to the students' needs and could be edited from class to class as necessary.

An excellent example of such effectiveness was in the Keaton. Nicholas and Palmer (2007) study where games were used between periods of direct instructional learning. One of the games used in the Keaton et al. (2007) study incorporated dry erase marker boards. With the dry erase marker boards the children could practice segmenting and blending phonetic sounds and draw pictures that con-elated to the sight words being practiced. The participants were encouraged to write a story that coincided with their illustrations and incorporate the words they were learning. These student-generated stories, filtered and edited with a bit of instructor input, were prepared for publication. Such personalization and game-based integration led to a positive correlation of better reading and writing capabilities as a result of the study environment. The authors in the Keaton et al. (2007) study discussed the added benefits of the game-based teaching technique, where the positive reinforcement of playing a game contributed to motivated and involved pupils.

Motivation is an essential part of learning; emotional attachment must be correlated during such learning intervals for future enjoyment and recall to be present. Game-based learning allows for such emotions and motivation to be fostered while delivery of essential information occurs (Charlton et al. 2005).

Brennan and Miller (2000) conducted a study that focused on sight word instruction combined with American sign language (ASL). Sign language is a joyful activity that allows children to have fun while learning sight words (Brennan et al. 2(X)0). ASL can be viewed from a child's perspective as a game during a direct instructional teaching session. Such a method can help keep students attention during class. Within the Brennan et al. (2011) experiment, a total of 11 first grade participants were involved. Five students were randomly assigned to learn a total of five sight words through a flashcard only instructional method. The other six participants were chosen to learn the same five sight words using a combination of a flashcard instructional 
method combined with ASL. The period before post testing was 5 weeks. Each group was given 10 minutes per school day of instruction delivered by trained teaching interns. Sight words were delivered in the same order for both groups respectively during each of the 5 weeks. The children being taught the ASL learned the specific signs that accompanied the five sight words that were imparted, an example being that the word "house" was taught on a flashcard. The ASL sign for "house" was shown along with the flashcard in the group that received ASL instruction. A pre-test and post-test was administered to all eleven participants. Both groups demonstrated an increased ability to recognize sight words where the ASL method was more effective than the traditional flashcard method. Specific results recorded a $76 \%$ accuracy of sight words recognized when using the flashcard only method and a $96 \%$ accuracy of sight words recognized utilizing the ASL method.

\section{Conclusion}

There are four phases of sight-word development, once all phases have been successfully mastered, the process of memorizing sight words can commence, which will lead to literacy and fluency. Teaching sight words can be difficult because children have different learning styles. It is important that teachers are aware of such variety and cater to their pupils by incorporating varied teaching techniques. A distinct need for further research on teaching sight words is present, especially in the non-traditional teaching methods of game-based learning and newer methods of technology-based learning. As technology advances, opportunities to create new teaching styles emerge. It is important that these opportunities are not missed so that every single child may be reached within the classroom.

\section{References}

Arnold, E., Daniel, S., Goldston, D., Hickman, E., Reboussin, B., \& Wood, F. (2005). Severity of emotional and behavioral problems among poor and typical readers. Journal of Abnormal Child Psychology, 33(2), 205-17. Retrieved from http://www.ncbi.nlm.nih.gov/pubmed/15839498

Brennan, K. B., \& Miller, A. D. (2000). How many words can your students read? Using a sign language game to increase sight word recognition. Intervention in School And Clinic, 35(3), 147-50. http://dx.doi.org/10.1177/105345120003500303

Browder, D. M., \& Lalli, J. S. (1991). Review of research on sight word instruction. Research in developmental disabilities, 203-228. http://dx.doi.org/10.1016/0891-4222(91)90008-G

Casey, S. D. (2008). A Comparison of within- and across-session progressive time delay procedures for teaching sight words to individuals with cognitive delays. Behavior Analyst Today, 9(3-4), 162-171.

Charlton, B., Williams, R., \& McLaughlin, T. F. (2005). Educational games: A technique to 
accelerate the acquisition of reading skills of children with learning disabilities. International Journal of Special Education, 20(2), 66-72.

Conners, F. (2003). Reading skills and cognitive abilities of individuals with mental retardation. International review of research in mental retardation, 27, 191-229. http://dx.doi.org/10.1016/S0074-7750(03)27006-3

Didden, R., Prinsen, H., \& Sigafoos, J. (2000). The blocking effect of pictorial prompts on sight-word reading. Journal of Applied Behavior Analysis, 33(3), 317-20. http://dx.doi.org/10.1901/jaba.2000.33-317

Ehri, L. C. (1991). Development of the ability to read words. Handbook of Reading Research, 2(1), 383-417.

Ehri, L. C. (1994). Development of the ability to read words: Update. Theoretical Models and Processes of Reading, 4(1), 323-358.

Ehri, L. C. (1995). Phases of development in learning to read words by sight. Journal of $\begin{array}{llll}\text { Research in } \quad \text { Reading, } & 18(2), & 16-125 .\end{array}$ http://dx.doi.org/10.1111/j.1467-9817.1995.tb00077.x

Ehri, L. C. (2005). Learning to read words: Theory, findings, and issues. Scientific Studies of Reading, 9(2), 167-188. http://dx.doi.org/10.1207/s1532799xssr0902_4

Gambrell, L. B. (1996). Creating classroom cultures that foster reading motivation. The Reading Teacher, 50(1), 14-25.

Gaskin, I. W., Ehri, L. C., Cress, C., O'Hara, C., \& Donnelly, K. (1997). Procedures for word learning: Making discoveries about words. The Reading Teacher, 50(4), 312-327.

Grossen, B., \& Center for the Future of Teaching and Learning, S. A. (1997). 30 Years of research: What we now know about how children learn to read.

Johnston, F. R. (2000). Word learning in predictable text. Journal of Educational Psychology, 92(2), 248-255. http://dx.doi.org/10.1037/0022-0663.92.2.248

Keaton, J., Palmer, B., \& Nicholas, K. (2007). Direct instruction with playful skill extensions: Action research in emergent literacy development. Reading Horizons, 47(3), 229-250.

Kupzyk, S., Daly, E., \& Andersen, M. N. (2011). A comparison of two flash-card methods for improving sight-word reading. Journal Of Applied Behavior Analysis, 44(4), 781-792. http://dx.doi.org/10.1901/jaba.2011.44-781

Law, J., Rush, R., Schoon, I., \& Parsons, S. (2009). Modeling developmental language difficulties from school entry into adulthood, Journal of Speech, Language, and Hearing Research, 52, 1401-1406. http://dx.doi.org/10.1044/1092-4388(2009/08-0142)

Meadan, H., Stoner, J. B., \& Parette, H. P. (2008). Sight word recognition among young children at-risk: Picture-supported vs. word-only. Assistive Technology Outcomes And Benefits, 5(1), 45-58. 
Mechling, L. C., Gast, D. L., \& Krupa, K. (2007). Impact of smart board technology: An investigation of sight word reading and observational learning. Journal Of Autism and Developmental Disorders, 37(10), http://dx.doi.org/10.1007/s10803-007-0361-9

National Reading Panel (2000). Teaching children to read: An evidence-based assessment of the scientific research literature on reading and its implications for reading instruction. Washington, DC: National Institute of Child Health and Human Development.

Rivera, M. O., Koorland, M. A., \& Fueyo, V. (2002). Pupil-made pictorial prompts and fading for teaching sight words to a student with learning disabilities. Education and Treatment Of Children, 25(2), 197-207.

Rubin, D., \& Opitz, M. (Eds.). (2007). Diagnosis and improvement in reading instruction. Boston: Pearson.

Savage, R., Stuart, M., \& Hill, V. (2001). The role of scaffolding errors in reading development: Evidence from a longitudinal and correlational study. British Journal of Educational Psychology, 71, 1-13. http://dx.doi.org/10.1348/000709901158343

Sheehy, K. (2005). Morphing images: A potential tool for teaching word recognition to children with severe learning difficulties. British Journal of Educational Technology, 36(2), 293-301. http://dx.doi.org/10.1111/j.1467-8535.2005.00458.x

Sherman, J. (2011). Signing for success: Using american sign language to learn sight vocabulary. SRATE Journal, 20(2), 31-38.

Vacca, J., Vacca, R., Gove, M., Burkey, L., Lenhart, L., \& McKeon, C. (Eds.). (2009). Reading and learning to read. Boston: Pearson.

\section{Copyright Disclaimer}

Copyright reserved by the author(s).

This article is an open-access article distributed under the terms and conditions of the Creative Commons Attribution license (http://creativecommons.org/licenses/by/3.0/). 